\title{
Procedural and follow up results with a new balloon expandable stent in unselected lesions
}

\author{
C di Mario, B Reimers, Y Almagor, I Moussa, L Di Francesco, M Ferraro, M B Leon, \\ K Richter, A Colombo
}

\begin{abstract}
Objective-To assess the clinical and angiographic results of the first clinical application of a new balloon expandable stent, the NIR stent, characterised by high longitudinal flexibility and low profile before expansion, and by high radial support and minimal recoil and shortening after expansion.
\end{abstract}

Design-Single centre survey of unselected lesions in consecutive patients. Setting-Tertiary referral centre.

Patients and lesions-93 stents of various length $(9,16$, and $32 \mathrm{~mm})$ were implanted in 64 lesions in 41 patients. Twenty lesions $(31 \%)$ were longer than $15 \mathrm{~mm}$, and 17 lesions $(27 \%)$ were located in vessels with a diameter smaller than $2.5 \mathrm{~mm}$. Extreme tortuosity of the proximal vessel was present in 15 lesions (23\%). All patients were treated with aspirin and ticlopidine. All lesions were evaluated before and after treatment by quantitative angiography, and in 47 lesions $(75 \%)$ the stent expansion was also controlled by intracoronary ultrasound. Clinical follow up was available in all patients and angiographic follow up was performed in 53 lesions (84\%), at a mean (SD) interval of 5.4 (1.7) months.

Results-Deployment of the stent failed in two lesions (3\%). Minimum lumen diameter increased from $1.01(0.54) \mathrm{mm}$ to 2.94 $(0.49) \mathrm{mm}$, and diameter stenosis decreased from $66(15) \%$ to $7(11) \%$. There was one in-hospital non- $Q$ wave myocardial infarction, one sudden death after 40 days, and 17 target lesion revascularisations (27\%). Angiographic restenosis ( $\geqslant 50 \%$ diameter stenosis) was documented in 19 lesions (36\% of all lesions with angiographic follow up), with an average residual diameter stenosis of $43(21) \%$ and minimum lumen diameter of $1.63(0.74) \mathrm{mm}$. Restenosis was more common in vessels with a reference diameter $<2.5 \mathrm{~mm}(45 \%)$ and for lesions longer than $15 \mathrm{~mm}(46 \%)$.

Conclusions-The NIR stent could be used successfully in most lesions, achieving optimal angiographic results with very few in-hospital or subacute cardiac events. The angiographic restenosis rate and need for target lesion revascularisation remained high in this unfavourable lesion subset, especially in small vessels and long lesions.

(Heart 1998;79:234-241)
Keywords: coronary stenting; quantitative angiography; intravascular ultrasound; restenosis

Large multicentre randomised trials have shown that tubular slotted stents reduce the incidence of cardiac events and restenosis compared with balloon angioplasty. ${ }^{12}$ The currently available stents, however, are fairly rigid and difficult to insert into tortuous or distal vessels, and multiple overlapping stents are required to treat long lesions.

We report the immediate and long term results obtained in 64 unselected lesions in a consecutive series of 41 patients using a stent of new design (NIR, Medinol, Tel Aviv, Israel), with high flexibility and available in lengths of up to $32 \mathrm{~mm}$.

\section{Methods}

\section{PATIENTS AND LESIONS}

Characteristics of the patients and the angiographic lesions are given in table 1. All patients gave written witnessed informed consent. Two experienced angiographers judged that the lesion was difficult to approach with a regular slotted stent because of one or more unfavourable characteristics such as lesion length $\geqslant 15 \mathrm{~mm}$, distal vessel location (fig 1), or extreme vessel tortuosity. One or more of these conditions was present in 39 lesions $(61 \%)$. Extreme vessel tortuosity was defined as the presence of two successive angulations of $\leqslant 90^{\circ}$ of the proximal vessel or at the stenosis site, or a single acute angle $\leqslant 60^{\circ}$ (as in the shepherd's crook right coronary artery of fig 2), judged in the most unfavourable projection and before wire insertion. The length of the stented segment was $25 \mathrm{~mm}$ in 43 lesions $(67 \%)$ and the reference vessel diameter was $<2.5 \mathrm{~mm}$ in 17 lesions $(27 \%)$.

STENT CHARACTERISTICS

The NIR stent used in this study was made of 75 or $100 \mu \mathrm{m}$ thick $316 \mathrm{~L}$ stainless steel sheets etched into a predetermined geometric pattern and then rolled and welded into a tubular configuration. The continuous uniform multicellular design with differential lengthening of cells confers high flexibility before expansion (fig 3). After deployment, the stent becomes a rigid scaffold which maintains high radial force.

\section{PROCEDURE}

Although the stent can be inserted through $6 \mathrm{~F}$ guiding catheters, $8 \mathrm{~F}$ large lumen guiding catheters were used in most cases to allow the insertion of the intravascular ultrasound 
Table 1 Patient and lesion characteristics

\begin{tabular}{|c|c|}
\hline & Number \\
\hline Study patients & 41 \\
\hline Age (years) (mean (SD)) & $59(10)$ \\
\hline Male $(\%)$ & $36(88)$ \\
\hline Previous myocardial infarction (\%) & $20(49)$ \\
\hline Previous balloon angioplasty (\%) & $5(12)$ \\
\hline Braunwald II-III unstable angina (\%) & $6(15)$ \\
\hline Single vessel disease $(\%)$ & $9(22)$ \\
\hline Multivessel disease $(\%)$ & $32(78)$ \\
\hline Left ventricular ejection fraction (mean (SD)) & $61(10)$ \\
\hline Lesions attempted & 64 \\
\hline Lesions/patient (mean (SD)) & $1.6(0.3)$ \\
\hline \multicolumn{2}{|l|}{ Vessel treated } \\
\hline Left anterior descending/diagonal (\%) & $32(50)$ \\
\hline Left circumflex/marginal (\%) & $17(26)$ \\
\hline Right coronary (\%) & $14(22)$ \\
\hline Venous graft $(\%)$ & $1(2)$ \\
\hline \multicolumn{2}{|l|}{ Lesion location } \\
\hline Ostial (\%) & $6(9)$ \\
\hline Proximal (\%) & $21(33)$ \\
\hline Mid-segment (\%) & $28(44)$ \\
\hline Distal (\%) & $9(14)$ \\
\hline \multicolumn{2}{|l|}{ Modified AHA/ACC lesion type } \\
\hline $\mathrm{A}(\%)$ & $4(6)$ \\
\hline $\mathrm{B}_{1}(\%)$ & $14(22)$ \\
\hline $\mathrm{B}_{2}(\%)$ & $30(47)$ \\
\hline $\mathrm{C}(\%)$ & $16(25)$ \\
\hline Tortuous proximal vessel (\%) & $15(23)$ \\
\hline \multicolumn{2}{|l|}{ Lesion length $(\mathrm{mm})$} \\
\hline$<5(\%)$ & $1(2)$ \\
\hline $5-9.9(\%)$ & $25(39)$ \\
\hline $10-14.9(\%)$ & $18(28)$ \\
\hline $15-19.9(\%)$ & $11(17)$ \\
\hline$\geqslant 20(\%)$ & $9(14)$ \\
\hline \multicolumn{2}{|l|}{ Reference lumen diameter ( $\mathrm{mm}$ ) } \\
\hline$<2.5(\%)$ & $17(27)$ \\
\hline $2.5-2.99(\%)$ & $22(34)$ \\
\hline $3.0-3.49(\%)$ & $15(23)$ \\
\hline$\geqslant 3.5(\%)$ & $10(16)$ \\
\hline
\end{tabular}

catheter or the Rotablator (seven lesions), when necessary; $10 \mathrm{~F}$ guiding catheters were used in the two lesions pretreated with directional atherectomy. After removal of the lubricious coating of the balloon with sterile ethylic ether, the stent was placed on the deflated balloon over a 16 gauge Intracath and firmly crimped manually in a central position on low compliance balloons of appropriate diameter (range 2.5 to $4.0 \mathrm{~mm}$ ) and length (10 to $40 \mathrm{~mm}$ ), selected to maintain a balloon to artery ratio not exceeding 1.2 and to cover the entire length of the diseased segment. The stent was directly expanded at high pressure ( $>16$ atmospheres). When necessary, on the basis of angiographic appearances and the results of the ultrasound examination, postdilatation with larger balloons or a higher pressure was performed. The maximum balloon pressure was 17 (3) atmospheres.

QUANTITATIVE ANGIOGRAPHIC ANALYSIS

A third generation quantitative angiographic analysis (QCA) system (version 3.0 Cardiovascular Imaging System, MEDIS, Leiden, The Netherlands) was used to analyse $35 \mathrm{~mm}$ cineangiograms filmed in matched views during maximum vasodilatation (intracoronary isosorbide dinitrate, 1-3 mg) before and after treatment and at follow up. We used catheter calibration and computer assisted edge detection (minimum cost algorithm or, for irregular lesions before treatment, gradient field transform) (fig 4). ${ }^{3}$ After stent implantation, the stented segment was excluded for the calcula- tion of the interpolated reference diameter, as previously described. ${ }^{4}$ Angiographic restenosis was defined as recurrence of $\geqslant 50 \%$ diameter stenosis within the stent or at the stent borders and distinguished in focal or diffuse (shorter or equal/longer than $10 \mathrm{~mm}$, respectively).

INTRACORONARY ULTRASOUND

Intracoronary ultrasound was performed in 47 lesions $(75 \%)$ using $2.9 \mathrm{~F}$ or $3.2 \mathrm{~F} 30 \mathrm{MHz}$ Monorail mechanical catheters and a CvisBoston Scientific Insight 3.0 console (Sunnyvale, California, USA). The catheter was inserted distal to the lesion and motorised pullback was performed at $0.5 \mathrm{~mm} / \mathrm{s}$ along the treated segment. On-line three dimensional reconstruction was routinely performed in the last 26 cases to facilitate review of images and measurement of length. ${ }^{5}$ Criteria used to optimise stent expansion and to perform the intracoronary ultrasound measurements have been reported previously. ${ }^{67}$

FOLLOW UP

For all patients, who were discharged one to two days after the procedure, a follow up visit or telephone call was done at one month. In all patients follow up angiography was scheduled at six months after stent implantation. In case of patient refusal or contraindication to angiographic restudy, a follow up visit or direct contact with patient and referring cardiologist was performed.

\section{Results}

PROCEDURAL SUCCESS

The procedural data are reported in table 2 . The stents could be successfully implanted in 62 lesions (97\%).

In the second patient treated (fig 1), after successful insertion of a $32 \mathrm{~mm}$ stent in the distal left anterior descending coronary artery with a $3.0 \mathrm{~mm}$ low profile balloon, a second $32 \mathrm{~mm}$ stent mounted on a non-compliant $3.5 \mathrm{~mm}$ balloon could not be advanced up to the target lesion in the mid-segment of the left anterior descending coronary artery, and the inability to retrieve the stent into the guiding catheter resulted in embolisation of the stent to the lower limbs, without any clinical consequence at 20 months follow up. After further predilatation, another $32 \mathrm{~mm}$ NIR stent was successfully inserted with the low profile balloon used for the first insertion. It must be noted that in three other cases in which the initial deployment was unsuccessful, the stent could be withdrawn into the guiding catheter and was then successfully deployed after further predilatation or with the use of different guiding or balloon catheters or stiffer guide wires.

The other failure of deployment occurred in a patient with restenosis four months after implantation of three Palmaz-Schatz stents (model 154) in the mid-segment of the left anterior descending coronary artery. A subocclusive ostial stenosis of a diagonal branch was treated with a $3.0 \mathrm{~mm}$ balloon inserted through the stent struts. The insertion of a $9 \mathrm{~mm}$ NIR stent at the ostium of this diagonal 


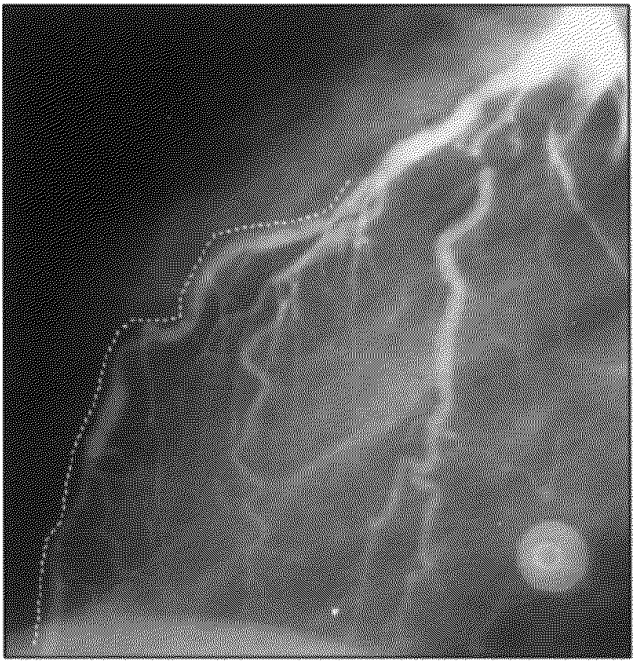

Baseline

\begin{tabular}{|ll|}
\hline Reference vessel & $2.11 \mathrm{~mm}$ \\
MLD & $0.70 \mathrm{~mm}$ \\
Diameter stenosis & $67 \%$ \\
\hline
\end{tabular}

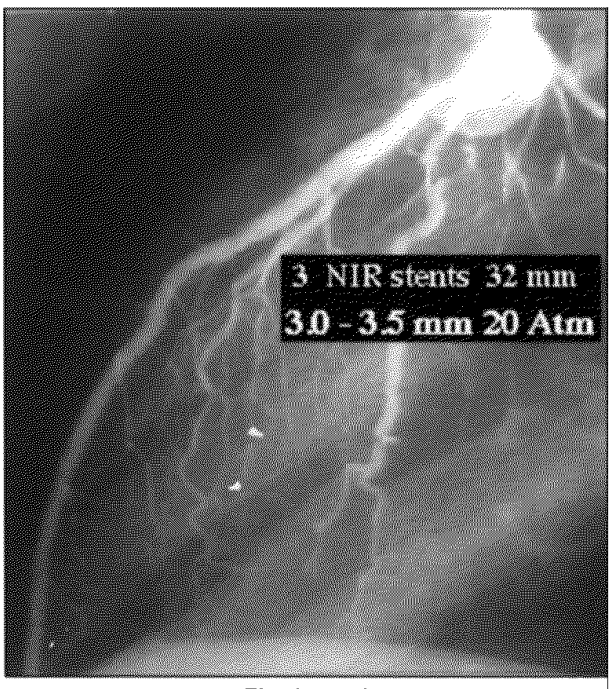

Final result

\begin{tabular}{|ll|}
\hline Reference vessel & $2.65 \mathrm{~mm}$ \\
MLD & $2.82 \mathrm{~mm}$ \\
Diameter stenosis & $-7 \%$ \\
\hline
\end{tabular}

Figure 1 Example of a long lesion of the mid-distal segment of the left anterior descending coronary artery treated with $3 \times 32 \mathrm{~mm}$ NIR stents. MLD, minimum lumen diameter.

branch was unsuccessful but the stent could easily be withdrawn and a $9 \mathrm{~mm}$ AVE Microstent II was implanted. Bifurcation lesions were successfully treated in three other cases by advancing a NIR stent through the struts of another NIR stent, previously implanted in the main vessel (fig 5A), or using two stents implanted side by side from the main vessel to the two daughter branches (fig 5B).

One non-Q-wave myocardial infarct occurred in a patient treated with bail-out stenting for a long, occlusive spiral dissection of the right coronary artery involving the distal arterial branches, in which two Palmaz-Schatz stents were already implanted. After failure to implant a third Palmaz-Schatz stent (bare or with delivery system) to cover the distal part of the dissection, an NIR stent was passed through the previously implanted stents. In this patient, a 41 year old female renal transplant recipient with a preprocedure left ventricular ejection fraction of less than $30 \%$, a bolus dose and a 24 hour infusion of the glycoprotein IIb/ IIIa platelet receptor inhibitor abciximab (ReoPro, Lilly/Centocor, The Netherlands) was

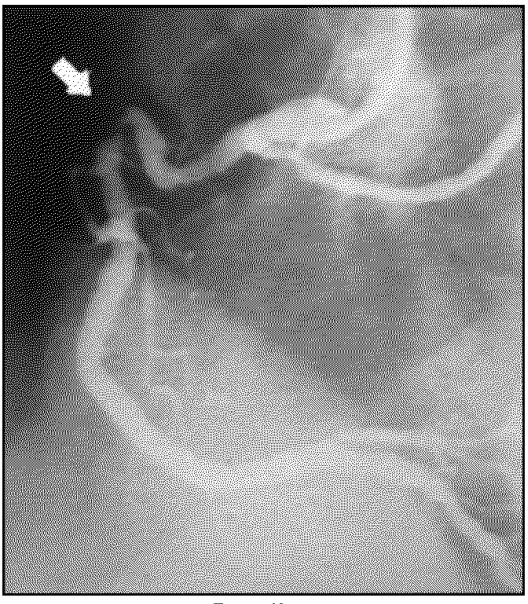

Baseline

\begin{tabular}{|ll|}
\hline Reference vessel & $3.99 \mathrm{~mm}$ \\
MLD & $1.35 \mathrm{~mm}$ \\
Diameter stenosis & $66 \%$ \\
\hline
\end{tabular}

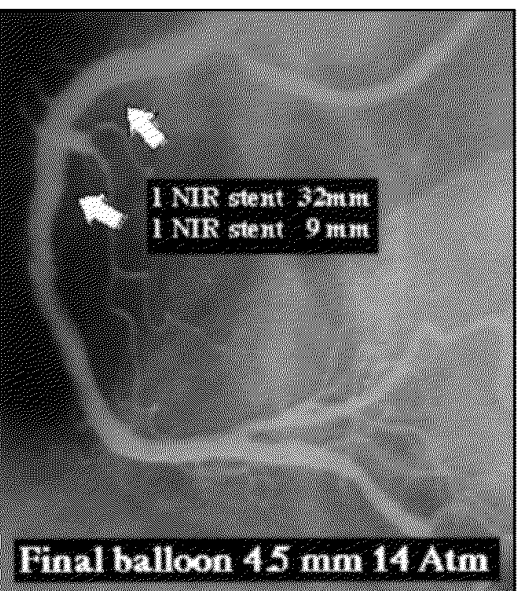

Final result

\begin{tabular}{|ll|}
\hline Reference vessel & $4.61 \mathrm{~mm}$ \\
MLD & $4.04 \mathrm{~mm}$ \\
Diameter stenosis & $12 \%$ \\
\hline
\end{tabular}

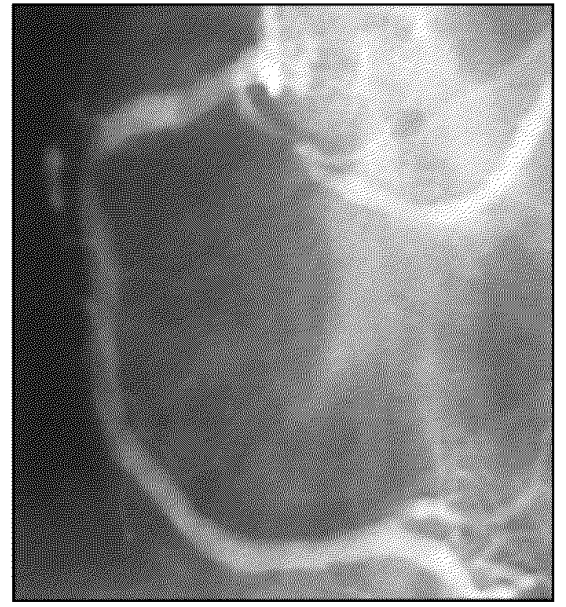

6 months FU

\begin{tabular}{|ll|}
\hline Reference vessel & $3.35 \mathrm{~mm}$ \\
MLD & $2.05 \mathrm{~mm}$ \\
Diameter stenosis & $39 \%$ \\
\hline
\end{tabular}

Figure 2 Example of very tortuous shepherd's crook proximal segment of a right coronary artery treated with two NIR stents. Note that a large lumen (minimum lumen diameter $(M L D)=2.05 \mathrm{~mm}$ ) is still maintained at six months' follow up (FU). 


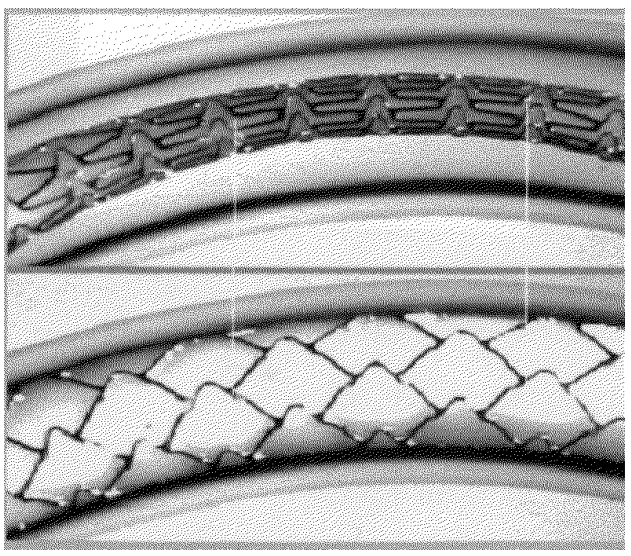

Figure 3 Magnified photograph of the NIR stent before (upper panel) and after (lower panel) expansion with a balloon inside a transparent plastic tube. Note the flexibility before expansion and the conformability to the curved tube after expansion. The line connects the junction of the segment that elongates during expansion with the segment that shortens during expansion, maintaining the total stent length almost unchanged during the expansion. Note the regular cellular design of the stent after expansion.

used and the patient was discharged after a hospital stay of five days.

Another procedural complication was contrast extravasation after high pressure dilatation with an oversized balloon of a diagonal branch, which sealed spontaneously after prolonged balloon inflation and intravenous administration of protamine sulphate $50 \mathrm{mg}$.

QUANTITATIVE ANGIOGRAPHIC AND ULTRASOUND ANALYSIS

The quantitative angiographic measurements before treatment, after stent deployment, and at follow up are given in table 3. Angiographic follow up was obtained in 33 of 41 patients $(80 \%)$ and in 53 of 63 lesions receiving a NIR stent $(84 \%)$. Angiographic restenosis $(\geqslant 50 \%$ diameter stenosis) was observed in $19 / 53$ lesions $(36 \%)$; it was focal in nine $(47 \%)$ and diffuse in $10(53 \%)$. Lesions with a reference vessel diameter $<2.5 \mathrm{~mm}$ had a significantly higher incidence of angiographic restenosis
Table 2 Procedural and follow up (one month) results

\begin{tabular}{lc}
\hline & Number \\
\hline Indications for stenting & \\
Elective (\%) & $52(81)$ \\
Restenosis (\%) & $5(8)$ \\
Suboptimal result (\%) & $5(8)$ \\
Threatened vessel closure (\%) & $2(3)$ \\
Pre-stenting lesion treatment & \\
No predilatation before stenting (\%) & $3(5)$ \\
Balloon dilatation (\%) & $51(79)$ \\
Rotational atherectomy (\%) & $7(11)$ \\
Directional atherectomy (\%) & $2(3)$ \\
Pullback atherectomy (\%) & $1(2)$ \\
Lesions successfully treated with the NIR & $63(98)$ \\
stent (\%) & \\
Stent/lesion (mean (SD)) & $1.56(0.5)$ \\
Stent used & \\
NIR 9 mm (\%) & $27(28)$ \\
NIR 16 mm (\%) & $48(50)$ \\
NIR 32 mm (\%) & $18(19)$ \\
Palmaz-Schatz 154 14 mm (\%) & $2(2)$ \\
AVE 12 mm (\%) & $1(1)$ \\
Nominal size final balloon (mm) (mean (SD)) & $3.4(0.4)$ \\
Balloon to vessel ratio (mean (SD)) & $1.24(0.21)$ \\
Vessel rupture after post-dilatation (\%) & $1(2)$ \\
Maximum balloon pressure (Atm) (mean (\%)) & $16.7(3.5)$ \\
IVUS attempted during procedure (\%) & $47(75)$ \\
IVUS failure (\%) & $4(8)$ \\
IVUS criteria met in the initial study (\%) & $19(40)$ \\
IVUS criteria met after post-dilatation (\%) & $13(28)$ \\
IVUS not repeated after post-dilatation (\%) & $5(11)$ \\
IVUS still suboptimal, final study (\%) & $6(13)$ \\
Patient treatment after stenting (\%) & $1.7(0.2)$ \\
Aspirin 100-300 mg & $1(2)$ \\
Aspirin 100-300 mg + ticlopidine 500 mg \\
Hospital stay after stenting (days) (mean (SD)) \\
Bleeding/vascular complications (\%) & 0 \\
Subacute closure at one month & $56(88)$ \\
\hline & \\
\hline & \\
\hline
\end{tabular}

than lesions located in larger vessels $(45 \% v$ $28 \%, \mathrm{p}<0.02)$. Lesion length $\geqslant 15 \mathrm{~mm}$ was also associated with an increased risk of restenosis $(46 \% v 20 \%$ for lesions $<15 \mathrm{~mm}$, $\mathrm{p}<0.01)$.

The complete examination of the stented segment with ultrasound was performed in 43 lesions $(68 \%)$. In four cases the ultrasound catheter was inserted but a rupture of the rotating cable occurred during the examination
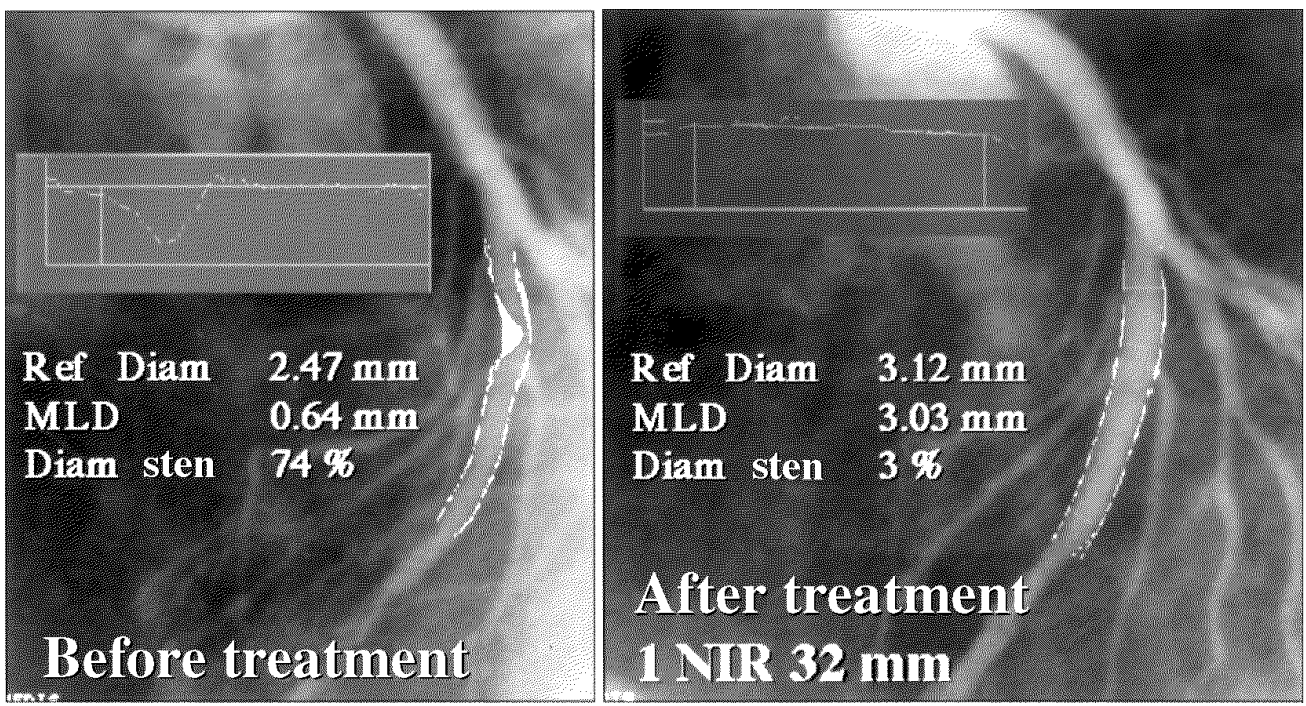

Figure 4 Quantitative angiographic measurements of a proximal lesion of the left anterior descending coronary artery before treatment and after high pressure expansion of a $32 \mathrm{~mm}$ NIR stent. MLD, minimum lumen diameter. 
A
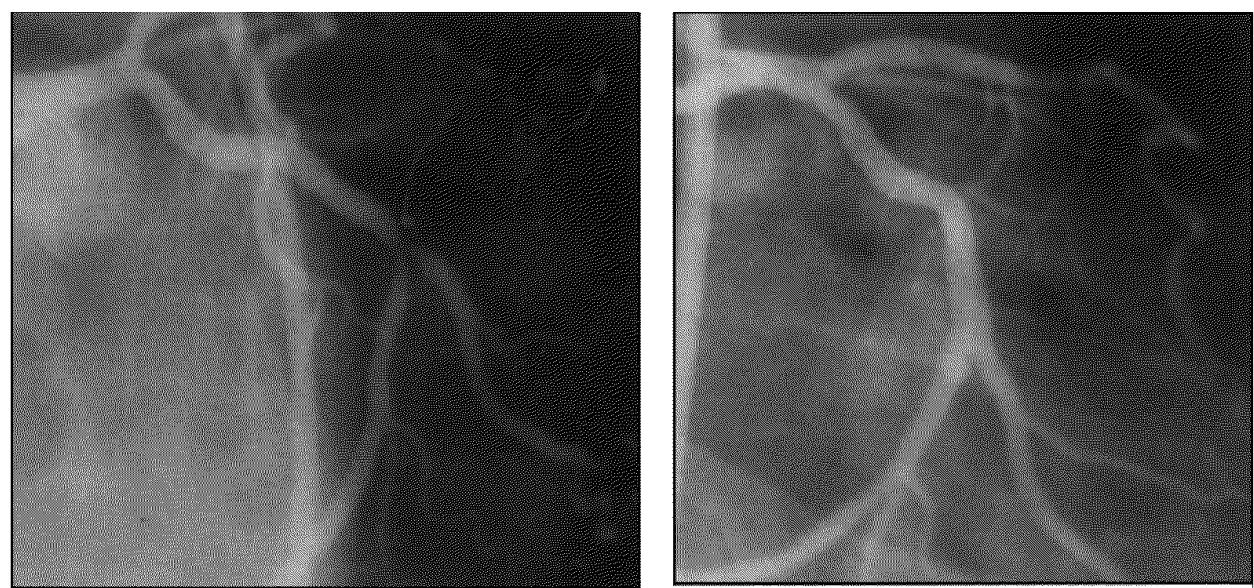

Atherectomy of both branches +2 NIR stents

B

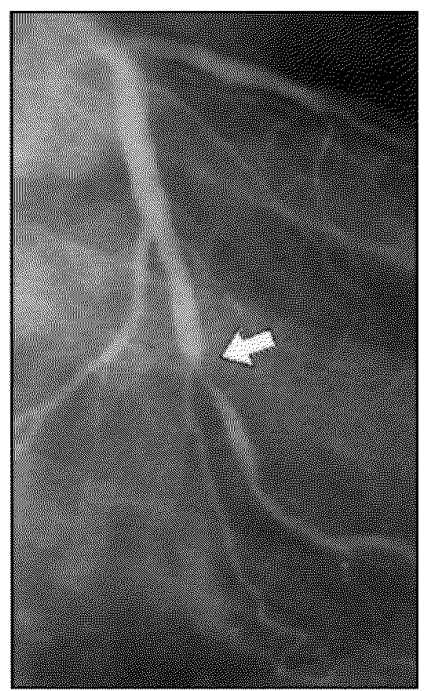

Baseline

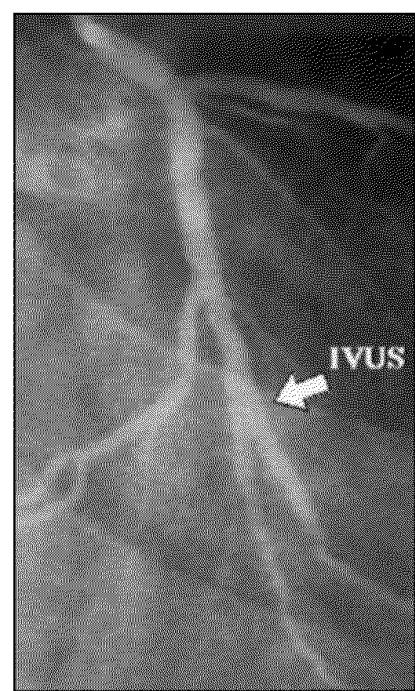

Final result

$9 \mathrm{~mm}$ NIR stent $\times 2$
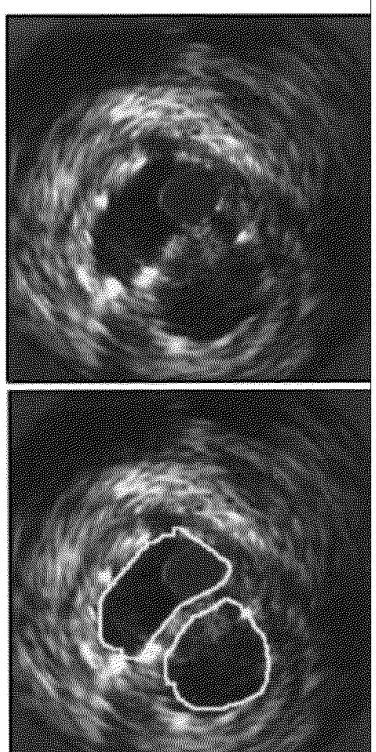

Figure 5 (A) Example of a bifurcational lesion of the left circumflex-obtuse marginal branch treated with directional atherectomy followed by implantation of a long $32 \mathrm{~mm}$ NIR stent in the left circumflex and a $9 \mathrm{~mm}$ NIR stent subsequently inserted through the struts of the previously implanted stent at the ostium of the obtuse marginal branch. (B) Left and mid-panel: Example of a bifurcational lesion of the left circumflex-posterolateral branch treated with the implantation of two $9 \mathrm{~mm}$ NIR stents, expanded side by side at high pressure in the segment between the two arrows. Right panels: Cross sectional ultrasound (IVUS) image obtained proximal to the bifurcation (arrowhead in the mid-panel) showing the two stents well apposed to the vessel wall on both sides and merging in a central, regular metallic carina in the centre of the artery.

because of the extreme tortuosity of the vessels examined. In the 38 lesions examined with ultrasound after the final balloon expansion (fig 6), optimal strut apposition was confirmed in all instances. An intrastent minimum cross sectional lumen area larger than the distal lumen area was obtained in 32 lesions $(84 \%$ of the lesions controlled at the end of the procedure). The final result remained suboptimal in six lesions $(16 \%)$ in which the stent

Table 3 Quantitative coronary angiography results

\begin{tabular}{llll}
\hline & $\begin{array}{l}\text { Before stent } \\
(n=63)\end{array}$ & $\begin{array}{l}\text { After stent } \\
(n=63)\end{array}$ & $\begin{array}{l}\text { At follow up } \\
(n=53)\end{array}$ \\
\hline Minimum lumen diameter (mm) & $1.01(0.54)$ & $2.94(0.49)$ & $1.63(0.74)$ \\
Reference diameter (mm) & $2.86(0.54)$ & $3.17(0.52)$ & $\begin{array}{l}2.76(0.52) \dagger \\
\text { Diameter stenosis (\%) }\end{array}$ \\
$\begin{array}{l}66(15) \\
\text { Lesion length (mm) }\end{array}$ & $12.15(5.24)$ & $73)^{\star}$ & $8.77(6.27)$ \\
\hline
\end{tabular}

Values are mean (SD).

${ }^{\star} \mathrm{p}<0.05 v$ before stent; $\mathrm{tp}<0.05 v$ before stent and $v$ after stent.

lumen area still did not match the distal area, or where residual stenotic segments or marginal tears were present. In these instances, a further increase in balloon diameter or inflation pressure or the use of additional stents was not considered feasible or safe by the operator.

\section{CLINICAL FOLLOW UP}

No anticoagulant treatment was used in any case, including patients with suboptimal ultrasound results at the end of the procedure or those not examined with ultrasound. Antiplatelet treatment consisted in the combination of aspirin $100-300 \mathrm{mg} / \mathrm{d}$ and ticlopidine 500 $\mathrm{mg} / \mathrm{d}$. Both drugs were started at least two days before the procedure and continued indefinitely and for one month, respectively. The absence of systemic anticoagulation explains the low incidence of bleeding and vascular 


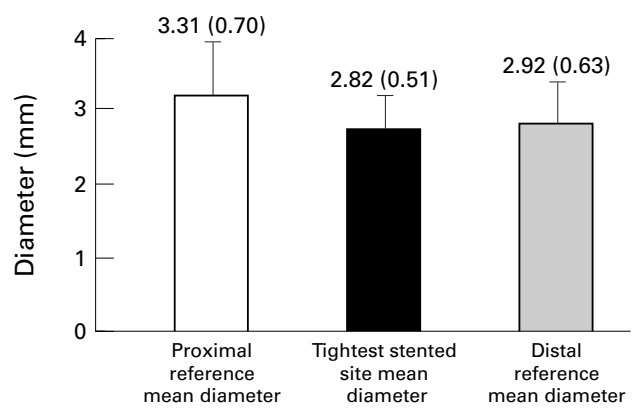

Figure 6 Bar graphs showing the quantitative ultrasound measurements after stent implantation.

complications (one femoral pseudoaneurysm successfully treated by ultrasound guided manual compression in a patient with extreme obesity).

Clinical follow up results at six months are shown in table 4 . As already stated, one sudden death $(2 \%)$ occurred at 40 days after the stent procedure in a woman with renal transplant, low left ventricular ejection fraction, and periprocedural non-Q-wave myocardial infarction. No other myocardial infarctions were observed during the six months follow up. Recurrence of anginal symptoms or positive exercise test, or both, was present in 10 of 41 patients $(24 \%)$. Target lesion revascularisation was performed in 17 of 64 lesions (27\%), 16 by percutaneous and one by surgical revascularisation.

\section{Discussion}

Slotted tube stents with interlinked struts creating a cellular mesh offer high radial support and optimal plaque scaffolding but are hampered by their limited flexibility. This study confirmed that the high longitudinal

Table 4 Clinical and angiographic follow up results

\begin{tabular}{|c|c|}
\hline & Number \\
\hline \multicolumn{2}{|l|}{ Patients } \\
\hline Six months of clinical follow up obtained (\%) & $41 / 41(100)$ \\
\hline Mean clinical follow up (months) (mean (SD)) & $8.9(3.6)$ \\
\hline Death $(\%)$ & $1 / 41(2)$ \\
\hline Non-Q wave myocardial infarction (\%) & $1 / 41(2)$ \\
\hline Subacute stent thrombosis at one month (\%) & $0 / 41(0)$ \\
\hline Recurrence of angina symptoms (\%) & $10 / 41(24)$ \\
\hline Repeat PTCA for restenosis (\%) & $9 / 41(22)$ \\
\hline CABG $(\%)$ & $1 / 41(2)$ \\
\hline \multicolumn{2}{|l|}{ Lesions } \\
\hline Angiographic follow up obtained (\%) & $53 / 63(84)$ \\
\hline Time to follow up (months) (mean (SD)) & $5.4(1.7)$ \\
\hline Target lesion revascularisation (\%) & $17 / 63(27)$ \\
\hline Repeat PTCA $(\%)$ & $16 / 63(25)$ \\
\hline CABG (\%) & $1 / 63(2)$ \\
\hline$\geqslant 50 \%$ restenosis treated medically $(\%)$ & $2 / 63(3)$ \\
\hline$\geqslant 50 \%$ diameter restenosis $(\%)^{\star}$ & $19 / 53(36)$ \\
\hline Diffuse ( $\geqslant 10 \mathrm{~mm}$ length) (\%) & $10 / 19(53)$ \\
\hline Focal (<10 mm length) $(\%)$ & $9 / 19(47)$ \\
\hline \multicolumn{2}{|l|}{ Patients } \\
\hline Patients without angiographic follow up (\%) & $8 / 41(20)$ \\
\hline Died $(\%)$ & $1 / 8(13)$ \\
\hline CCS class I + positive stress test (\%) & $1 / 8(13)$ \\
\hline Asymptomatic + negative stress test $(\%)$ & $6 / 8(74)$ \\
\hline
\end{tabular}

$\star$ Per lesion with angiographic follow up.

CABG, coronary artery bypass graft; CCS, Canadian Cardiovascular Society; PTCA, percutaneous transluminal coronary angioplasty. flexibility and low profile of this new stent facilitates stent insertion, allowing successful stent implantation even in anatomically unfavourable conditions. When appropriately expanded at high pressure, the stent could achieve a lumen size well matching the lumen of the adjacent reference segments, as confirmed by quantitative angiography and intracoronary ultrasound. The smooth angiographic appearance and regular circular lumen observed with ultrasound after stenting, the absence of articulations facilitating plaque prolapse, and the absence of gaps or strut overlapping when long lesions are treated with a single NIR stent instead of multiple shorter stents are characteristics which compare favourably with other mesh, slotted tube, or coil stents.

The poor radio-opacity of the stent, especially after expansion, and the risk of stent loss are persistent limitations of this stent and of this technique of implantation. In our experience, these limitations can be partially overcome by using an optimal lesion predilatation, preceded by rotational atherectomy for highly calcified lesions, and by mounting the stent on low profile balloons without lubricant coating and with a double radio-opaque marker (proximal and distal). A more effective solution has been the recent introduction of gold plated NIR stent (NIR-Royal), with increased visibility at fluoroscopy, and of delivery systems with the stent firmly premounted on balloons matching the stent lengths $(13,20$, $36 \mathrm{~mm}$ ) and with proximal and distal markers (NIR Primo, BS-Scimed, Maple Groove, Minnesota, USA). Another recent modification which could improve on the results reported in this study is the availability of stents containing seven attached cells in the circumference instead of the nine used in this study. This modification not only improves the flexibility of the stent but allows a lower metal to vessel surface ratio when deployed in vessels of less than $3.5 \mathrm{~mm}$ diameter, maintaining a similar radial support to the previous nine cell configuration. For vessels smaller than $2.5 \mathrm{~mm}$, a five cell configuration is also undergoing initial clinical testing.

The results of the multicentre trials STRESS and BENESTENT ${ }^{12}$ and the use of aspirin and ticlopidine instead of full anticoagulation $^{9-12}$ have greatly increased the number of stent implantations worldwide. The previous randomised clinical trials were restricted to focal lesions in straight proximal segments of the vessel which constitute the minority of anatomical conditions observed in patients with coronary artery disease, leaving most cases to alternative types of treatment (plain balloon angioplasty, rotational atherectomy, bypass surgery). This study shows that new stent designs can expand the indications for stent implantation and obtain satisfactory immediate results in a subset of lesions not suitable for treatment with conventional stents.

Despite the optimal initial results, the angiographic restenosis rate and the need for target lesion revascularisation remained high, suggesting that the problem of restenosis after treatment of long lesions or small vessels 
cannot be solved by improvements in stent design alone. This restenosis rate $(36 \%)$ might be a partial overestimate because in this study all the symptomatic patients underwent the angiographic follow up and $16 \%$ of the asymptomatic patients did not. Recently, however, a multicentre registry of consecutive implantation of the NIR stent in a large patient population (341 lesions) without angiographic follow up (FINESS I, first international NIR endovascular stent study) has shown that major cardiac events (mainly target lesion revascularisation) occurred in $34.5 \%$ of the patients with a stented segment longer than $40 \mathrm{~mm} .^{13}$

The interpretation of these results should take into account the results reported with balloon angioplasty or with the use of conventional stents in similar lesions. Angiographic restenosis rates after balloon angioplasty of long lesions are reported to be as high as $58 \%$, lesion length being a strong predictor of restenosis. ${ }^{14} 15$ The use of long balloons and rotational atherectomy is associated with a lower incidence of acute complications but has not modified the high risk of restenosis in these lesions. ${ }^{16-18}$

The results of the ERBAC study (excimer laser, rotational atherectomy and balloon angioplasty comparison) are of special interest because this study included consecutive lesions mainly (95\%) of AHA-ACC type B and C, randomised to one of the three treatment modes. ${ }^{19}$ In comparison with the lesions enrolled in our own study, in the balloon angioplasty arm of the ERBAC study the lesions were slightly shorter (10.6 (7.5) $\mathrm{mm} v 12.2$ (5.2) $\mathrm{mm}$ ) but the reference vessel diameter was similar $(2.93 \quad(0.62) \mathrm{mm} \quad v \quad 2.86$ $(0.54) \mathrm{mm})$. Vessel tortuosity and lesion angulation were excluded by protocol. Despite this selection of more favourable lesions overall, procedural success was only $79.7 \%$ marginally increased after crossing over to laser or rotational atherectomy-and the angiographic restenosis rate was $47 \%$. In the other two randomisation arms, excimer laser and rotational atherectomy significantly increased immediate success but were associated with an even higher angiographic restenosis rate (59\% and $57 \%$, respectively).

A second question is whether the new design of the NIR stent increases or decreases the restenosis rate in comparison with the classical diamond shaped design of the Palmaz-Schatz stent. Our study cannot answer this question because in most cases the lesions selected were not amenable to or were unfavourable for implantation of a conventional Palmaz-Schatz stent. Matching for lesion length and vessel size is unlikely to ensure full concordance of the lesion characteristics, since qualitative criteria (for example, a lesion in a bend) may also influence restenosis because of the hinging effect of any slotted tube stent (edge restenosis). For multiple stent implantation, restenosis rates between $30 \%$ and $63 \%$ are reported. ${ }^{20}{ }^{21}$ Analysis of our database of 2853 stented lesions indicates that when the lesions are divided into three groups according to the length of the stented segment $(\leqslant 20 \mathrm{~mm}$, between 20 and $35 \mathrm{~mm}$, and $\geqslant 35 \mathrm{~mm}$ ) the restenosis rates were $19 \%, 31 \%$, and $39 \%$, respectively. ${ }^{22}$ For lesions longer than $20 \mathrm{~mm}$, the angiographic restenosis rate remained $48 \%$, as it did when a single stent was used to cover the entire lesion. ${ }^{22}$ When the lesions are divided according to the reference vessel diameter (781 lesions in vessels $<3 \mathrm{~mm}$ and 891 lesions in vessels $\geqslant 3 \mathrm{~mm}$ ), a highly significant difference in restenosis rate was observed (angiographic restenosis rate of $32 \%$ and $21 \%$, respectively, $\mathrm{p}<0.001) .^{23}$ To put these data in perspective, the restenosis rate in our laboratory after high pressure implantation of a single $15 \mathrm{~mm}$ Palmaz-Schatz stent $(\mathrm{n}=155)$ or a $16 \mathrm{~mm}$ NIR stent $(\mathrm{n}=68)$ are $16.5 \%$ and $13.3 \%$, respectively (NS). In the absence of ongoing randomised trials comparing the Palmaz-Schatz and NIR stents, the completion of the angiographic follow up of the FINESS II trial, in which BENESTENT-like lesions were treated with single $16 \mathrm{~mm}$ NIR stents, will allow a comparison of similar basal angiographic characteristics, but different types of stent, in large consecutive lesion groups analysed in the same core laboratory.

\section{CONCLUSION}

In an unselected lesion population, the NIR stent could be deployed successfully and achieved optimal angiographic and ultrasound results with a very low incidence of adverse cardiac events in the first month after implantation. The incidence of target lesion revascularisation and restenosis, however, remained high, especially in long lesions and small vessels.

1 Fischman DL, Leon MB, Baim DS, et al. A randomized comparison of coronary-stent placement and balloon angioplasty in the treatment of coronary artery disease. N Engl f Med 1994;331:496-501.

2 Serruys PW, de Jaegere P, Kiemeneij F, et al, on behalf of the Benestent Study Group. A comparison of balloonexpandable-stent implantation with balloon angioplasty in patients with coronary artery disease. $N$ Engl f Med 1994 ; 331:489-95.

3 Zwet PMJ van der, Reiber JHC. A new approach to the quantification of complex lesion morphology: the gradient field transform; basic principles and validation results. $f$ Am Coll Cardiol 1994;24:216-24.

4 Reimers B, Di Mario C, Di Francesco L, et al. New approach to quantitative angiographic assessment after stent implantation. Cathet Cardiovasc Diagn 1997;40:3437.

5 Di Mario C, von Birgelen C, Prati F, et al. Threedimensional reconstruction of two dimensional ultrasound. Clinical or research tool? Br Heart 7 1955;73(suppl 2):2633.

6 Nakamura S, Colombo A, Gaglione A, et al. Intracoronary ultrasound observations during stent implantation. Circulation 1994;89:2026-34.

7 Goldberg SL, Colombo A, Nakamura S, et al. Benefit of intracoronary ultrasound in the deployment of Palmazintracoronary ultrasound in the deployment of Paln

8 Di Mario C, Colombo A. Trousers-stents: how to choose the right size and shape? Cathet Cardiovasc Diagn 1997;41: the right

9 Colombo A, Hall P, Nakamura S, et al. Intracoronary stenting without anticoagulation accomplished with intravascular ultrasound guidance. Circulation 1995;91:1676-88.

10 Hall P, Nakamura S, Maiello L, et al. A randomized comparison of combined ticlopidine and aspirin therapy versus aspirin therapy alone after successful intravascular ultrasound-guided stent implantation. Circulation 1996;93: 215-22.

11 Karrillon GJ, Morice MC, Benveniste E, et al. Intracoronary stent implantation without ultrasound guidance and with replacement of conventional anticoagulation by antiplatelet therapy. 30 day clinical outcome of the

12 Schomig A, Neumann FJ, Kastrati A, et al. A randomized comparison of antiplatelet and anticoagulant therapy after the placement of coronary artery stents. $N$ Engl $\mathcal{F}$ Med 1996;334:1084-9. 
13 Almagor Y, Feld S, Kiemeneij F, et al. First International NIR Endovascular stent study (FINESS): clinical and angiographic results following elective and urgent stent implantation. F Am Coll Cardiol 1997;30:847-59.

14 Bourassa MG, Lesperance J, Eastwood C, et al. Clinical, physiologic, anatomic and procedural factors predictive of
restenosis after PTCA. $\mathcal{F}$ Am Coll Cardiol 1991;18:368-76.

15 Hirchfeld JW, Schwartz JS, Jugo R, et al. Restenosis after coronary angioplasty: a multivariate statistical model to relate lesion and procedural variables to restenosis. $\mathrm{f} \mathrm{Am}$ Coll Cardiol 1991;18:647-56.

16 Cannon AD, Roubin GS, Hearn JA, et al. Acute angiographic and clinical results of long balloon percutaneous transluminal coronary angioplasty and adjuvant stenting for long narrowings. Am f Cardiol 1994;73:63541.

17 Bertrand ME, Lablanche JM, Lery F, et al. Percutaneous transluminal coronary rotary ablation with Rotablator. $\mathrm{Am}$ $\mathcal{f}$ Cardiol 1992;62:470-4.
18 Warth D, Leon M, O'Neill W, et al. Rotational atherectomy multicenter registry. Acute results, complications and six-month angiographic follow-up in 709 patients. $f \mathrm{Am}$ Coll Cardiol 1994;24:641-8.

19 Reifart N, Vandormael M, Krajcar M, et al. Randomized comparison of angioplasty of complex coronary lesions at single center. Excimer laser, rotational atherectomy and balloon comparison (ERBAC) study. Circulation 1997;96: 91-8.

20 Ellis SG, Savage M, Fishman D, et al. Restenosis after placement of Palmaz-Schatz stents in native coronary arteries. Circulation 1992;86:1836-44.

21 Reimers B, Di Mario C, Pasquetto G, et al. Long-term restenosis after multiple stent implantation. F Intervent Cardiol. [In press.]

22 Kobayashi Y, Di Mario C. Immediate and follow-up results following single long coronary stent implantation [abstract]. Circulation 1997;96:I-472.

23 Akiyama T, Goldberg SL Di Mario vessels [abstract]. Eur Heart $\mathcal{f}$ 1997;18:381. 